\title{
The degradability characteristics of fifty-four roughages and roughage neutral-detergent fibres as described by in vitro gas production and their relationship to voluntary feed intake
}

\author{
BY M. BLÜMMEL AND K. BECKER \\ Institute for Animal Production in the Tropics and Subtropics, University of Hohenheim (480), \\ D-70593 Stuttgart, Germany
}

(Received 14 July 1995 - Revised 24 September 1996 - Accepted 9 October 1996)

\begin{abstract}
Fifty-four roughages of known voluntary dry-matter intakes (DMI; range 7.8-35.2 g/kg live weight per d) were examined in vitro in a gas production test. Samples $(200 \mathrm{mg})$ of roughage and roughage neutral-detergent fibre (NDF) respectively were incubated in a mixed suspension of rumen contents for $96 \mathrm{~h}$ and the gas volumes recorded after $4,6,8,12,24,30,36,48,54,60$ and $96 \mathrm{~h}$. The kinetics of gas production were derived from the volume recordings described by the exponential equation $Y=A+B\left(1-e^{-c t}\right)$ where $A$ is the intercept and ideally reflects the fermentation of the soluble and readily available fraction of the feed, $B$ describes the fermentation of the insoluble (but with time fermentable) fraction and $c$ the fractional rate at which $B$ is fermented per $h ; A+B$ describes total fermentation. In vitro true dry matter (TD) and NDF degradabilities (NDF-D) after $24 \mathrm{~h}$ incubation were also determined. Of the variation in DMI, $75 \%$ was accounted for by the in vitro gas production parameters $A, B$ and $c$ in stepwise multiple regressions; $82 \%$ of the variation in DMI was explained by the parameters $\left(A^{\mathrm{NDF}}+B^{\mathrm{NDF}}\right)$ and $c^{\mathrm{NDF}}$ as obtained from the incubation of roughage NDF. The rate constants $(c)$ were less important than parameters related to the extent of gas production, accounting for only 6.5 (whole roughage) and 4.1 \% (NDF) of the variation in DMI. There was no statistical advantage in the use of the exponential model describing extent and rate of fermentation over some of the simple gas volume measurements: $75 \%$ of the variation in DMI was accounted for by in vitro gas production of whole roughage after $8 \mathrm{~h}$ of incubation. On average gas production from NDF measured from $24-96 \mathrm{~h}$ accounted for $81 \%$ of the variation in DMI. A combination of gas volume measurements after a short period of incubation $(4-8 \mathrm{~h})$ with a concomitant determination of NDF-D after many hours ( $\geq 24 \mathrm{~h}$ ) can render NDF preparations and long incubation times redundant. A method is suggested to obtain two results for DMI prediction in one single incubation. Of the variation in DMI $80 \%$ was accounted for by the incubation of $500 \mathrm{mg}$ whole roughage when incubation was terminated after $24 \mathrm{~h}$ and the residual undegraded substrate quantified.
\end{abstract}

Gas production: Neutral-detergent fibre: Voluntary feed intake

The voluntary feed intake of roughages is an essential factor in quality assessment (Minson, 1990). Whereas the determination of digestible nutrient content is competently dealt with by current in vitro or in sacco digestibility systems, the prediction of the likely consumption of roughages still presents problems.

Several authors (Van Soest et al. 1978; Ørskov et al. 1988) have indicated ways to improve the predictive capability of current in vitro or in sacco methods by using a kinetic rather than a static approach. More observations than the one provided, for example, by the widely used $48 \mathrm{~h}$ Tilley \& Terry (1963) digestibility are necessary. Two roughages may have the same $48 \mathrm{~h}$ digestibility but may very well differ when compared at times before or 
after. Van Soest et al. (1978) examined 187 roughages of known intake in vitro in a Tilley \& Terry (1963) system as modified by Goering \& Van Soest (1970). These authors determined the degradabilities nine times between 3 and $96 \mathrm{~h}$ incubation. Maximum correlation of in vitro degradability and dry-matter intake (DMI) occurred at $6 \mathrm{~h}$ incubation, $R^{2}$ being 0.62 . At $48 \mathrm{~h}$ incubation, in vitro digestibility explained only about $20 \%$ of the variation in DMI. These authors suggested the use of in vitro incubation times between 6 and $12 \mathrm{~h}$ for the prediction of DMI.

Ørskov et al. (1988) used time series measurements of degradabilities in sacco to fit an exponential equation reflecting extent and rate of fermentation. Ideally, this equation, $Y=A+B\left(1-\mathrm{e}^{-c t}\right)$, describes the degradability of the soluble and easily available fraction $A$ and the degradability of the insoluble (but with time fermentable) fraction $B$. The kinetics of fermentation are reflected by the fractional rate $c$ at which $B$ is degraded per hour. Several authors (Theodorou et al. 1991; Blümmel \& Ørskov, 1993; Khazaal et al. 1993) suggested gas production tests to describe rate and extent of fermentation. Attention was also given to the development of mathematical models describing the kinetics of gas production and providing for possible non-exponential courses of fermentation (Krishnamoorthy et al. 1991; Beuvink \& Kogut, 1993; France et al. 1993; Siaw et al. 1993).

The objective of the present study was to explore the potential of an in vitro gas production test for the estimation of rates and extent of fermentation of roughages and roughage neutral-detergent fibres (NDF) and the relevance of these estimates for the prediction of DMI.

\section{MATERIALS AND METHODS}

In vitro studies for the measurement of extent and rate of gas production

Rumen fluid and particulate matter were collected from two Hinterwälder (German Landrace) cattle kept exclusively on a hay diet of medium quality. A mixture of rumen fluid and particulate matter (approximately 60:40) was collected into pre-warmed $\mathrm{CO}_{2-}$ filled thermos bottles, transferred to and homogenized in a laboratory blender, strained and filtered through glass wool. All laboratory handling of rumen fluid was carried out under continuous flushing with $\mathrm{CO}_{2}$.

Portions of about $200 \mathrm{mg}$ sample were accurately weighed (in triplicate) into $100 \mathrm{ml}$ calibrated glass syringes, fitted with plungers as described by Menke et al. (1979) but modified as described by Blümmel \& Ørskov (1993). A total of $30 \mathrm{ml}$ medium consisting of $10 \mathrm{ml}$ rumen fluid and $20 \mathrm{ml}$ of a bicarbonate-mineral-distilled water mixture $(1: 1: 2$, by vol.) was injected into the syringes. Three blanks containing $30 \mathrm{ml}$ medium only were included at the beginning and at the end of every incubation. Triplicates of a reference hay of known gas production parameters were also included and incubations were repeated when standard gas volumes deviated more than $10 \%$ from average long-term volume observation. The gas production was recorded at 4, 6, 8, 12, 24, 30, 36, 48, 54, 60, 72 and $96 \mathrm{~h}$ incubation. Forty of the fifty-four substrates were incubated twice in rumen fluid collected on different days.

A similar procedure was followed for the incubation of NDF. About $1.5 \mathrm{~g}$ NDF was prepared by refluxing each roughage with neutral-detergent solution (NDS) (without sodium sulfite) according to the method of Van Soest \& Robertson (1985). After refluxing, the NDF was recovered on a filter crucible and rinsed at least ten times with hot distilled water to remove completely any remaining detergent solution. Approximately $200 \mathrm{mg}$ of dry NDF was accurately weighed directly from the crucible into the incubation syringe. 


\section{In vitro gas production and complementary determination of the truly undegraded substrate}

In these incubations the sample weights were increased from $200 \mathrm{mg}$ to $500 \mathrm{mg}$ so as to increase the mass of the residue to minimize the analytical error inherent in gravimetric determinations. To accommodate the higher short-chain fatty acid production with the larger sample, the bicarbonate buffer in the incubation medium was increased from $5 \mathrm{ml}$ to $10 \mathrm{ml}$. The increase in buffer volume was matched by an equal increase in volume of distilled water to keep the osmolality at similar levels to the one in routine incubations and a total of $40 \mathrm{ml}$ of this medium was incubated with $500 \mathrm{mg}$ air-dry substrate.

Gas volumes were recorded at 4, 6, 8, 10, 12 and $24 \mathrm{~h}$ incubation. After terminating the incubation at $24 \mathrm{~h}$ the entire residue in the incubation syringe was drained through the spike into a $600 \mathrm{ml}$ spoutless beaker. The syringe was washed three times with a total of $70 \mathrm{ml}$ NDS using a dispenser to dispense the NDS through the spike of the syringe (syringe and plunger were not dismantled throughout the operation). The NDS was added to the beaker after every rinsing. The residue was refluxed for $1 \mathrm{~h}$ in the detergent to extract microbial matter from the undegraded feed and the feed residue was recovered on a pre-tared filter crucible as described by Van Soest \& Robertson (1985). In this method the pepsin-HCl residue treatment (Tilley \& Terry, 1963) is replaced by NDS reflux which is more efficient in removing residual microbial contamination (Van Soest \& Robertson, 1985) leaving only the undegraded feed.

\section{Roughages analysed}

A total of fifty-four cereal straws and legume-hay-supplemented straws were examined. The work covered thirty-six variety trials of barley straws from the International Center for Agriculture Research in Arid Areas (ICARDA, Aleppo, Syria), ten barley and wheat straws from treatment trials with anhydrous $\mathrm{NH}_{3}$ (Rowett Research Institute, Aberdeen) and eight teff straws with legume-hay supplementation from the Debre Zeit Research Station in Ethiopia. Forty-four experiments were conducted with wether sheep and ten trials with steers. The Syrian trials were conducted with Awassi sheep weighing on average about 40 $\mathrm{kg}$ and a minimum of six sheep were used per trial except in seven treatments where leaves and stems were fed separately, when a minimum of four sheep were used. Five Ethiopian fat-tail sheep weighing on average $20 \mathrm{~kg}$ were used per treatment in the supplementation trials and ten Hereford steers with an average weight of $250 \mathrm{~kg}$ were used in the straw treatment trials. $\mathrm{N}$-deficient straws were supplemented to provide at least $1-1.2 \%$ of $\mathrm{N}$ in the diet. Soyabean cake was used as a $\mathbf{N}$ source in Syria and fishmeal was used in Scotland. The legume hay in the supplementation trials in Ethiopia was offered at a rate of $30 \%$ of the total feed on offer.

Voluntary feed intake was expressed as g/kg live weight (LW) per $\mathrm{d}$ and varied in the Syrian samples from 7.8 to $31.0 \mathrm{~g} / \mathrm{kg} \mathrm{LW}$ per d, in the Ethiopian samples from 20.3 to 35.2 $\mathrm{g} / \mathrm{kg} \mathrm{LW}$ per d (teff straw + legume hay) and in the Scottish samples from 9.3 to $14.7 \mathrm{~g} / \mathrm{kg}$ LW per $d$ respectively. There was no apparent difference in DMI on a live weight basis between sheep and steers used in this study. With the exception of the eight Ethiopian supplementation trials, the straws were incubated as fed, i.e. without supplement. In the case of the straw-legume-hay mix trials, straw and hay were incubated in the percentage offered. (In the in vivo trials legumes and straw were given separately and the legume hays were consumed entirely.) In all fifty-four trials straw refusals were $10-20 \%$ of the amount offered. 


\section{Mathematical and statistical analysis}

Time series measurements of gas volume recordings (average from triplicates) from 4-96 $\mathrm{h}$ of incubation were used for the curve fitting to express mathematically gas production with time. The exponential model $Y=A+B\left(1-\mathrm{e}^{-c t}\right)$ was chosen to describe the extent and rate of gas production. The equation parameters $A, B$ and $c$ were calculated by a non-linear regression procedure which minimizes the actual distances of the data points to the fitted curves by the Marquardt algorithm. The software employed for the calculation was Graphpad Inplot Version 3.2 (1990; San Diego, CA, USA). Average equation parameters were calculated from the forty substrates incubated twice. The remaining fourteen equations obtained from whole stover were based on one incubation run, as were all the NDF incubations and the gas volume/residue determinations.

The computer program SAS/STAT (Statistical Analysis Systems, 1988) was used for the multiple regression procedures (Proc. Reg., Selection Stepwise) to assess the relative importance of the various in vitro parameters in the prediction of voluntary feed intake. Pearsons correlation coefficients for the tests of interactions between parameters were calculated by the SAS/STAT Proc. Corr. procedures.

\section{RESULTS}

Extent and rate of in vitro gas production from roughage and roughage neutral-detergent fibre and the prediction of dry-matter intake

The extent $(A+B)$ of gas volumes from the incubation of $200 \mathrm{mg}$ roughage ranged from 33.6 to $68.7 \mathrm{ml}$, the average being $51.6 \mathrm{ml}$. The rates $(c)$ of gas production varied between 3.2 and $6.5 \%$ per $h$, the average being $4.9 \%$ per $h$. The intercept $(A)$ could be positive as well as negative, the overall mean of $A$ was negative. The gas volumes from the insoluble but fermentable fraction $B$ ranged from 33.6 to $74 \mathrm{ml}$ with a mean gas volume of $54.7 \mathrm{ml}$. Total gas volumes from $200 \mathrm{mg}$ NDF ranged from 41 to $79.3 \mathrm{ml}$, the average being $59.0 \mathrm{ml}$. More gas was produced from NDF than from unextracted substrate. The gas volumes associated with $B$ varied between 46.0 and $91.9 \mathrm{ml}$. The rates of NDF fermentation ranged from 1.49 to $6.53 \%$ per $h$ with a mean gas production rate of $4.34 \%$ per $h$. Gas volumes from the various parameters are summarized in Table 1.

The extent $(A+B)$ of in vitro gas production was little affected when forty substrates were incubated in rumen fluid collected on different days. The reproducibility of the rate of gas production $(c)$ was less accurate. A linear relationship describes the reproducibility as:

$$
\begin{array}{rll}
(A+B)_{1} & =(A+B)_{2}>Y=1.4(\text { SE } 1.7)+0.98(\text { SE 0.034)X } & R^{2} 0.97 n 40, \\
(c)_{1} & =(c)_{2}>Y=0.00019(\text { SE 0.0025) }+0.99(\text { SE 0.049)X } & R^{2} 0.91 n 40,
\end{array}
$$

where $(A+B)_{1},(A+B)_{2}$ and $(c)_{1},(c)_{2}$ denote the gas production parameters of the forty substrates obtained by two different incubations.

The rate constants of five roughages differed by more than $7 \%$ in the second incubation compared with the first one and were mainly responsible for the deviation from total agreement $\left(R^{2} 0.91\right.$ v. $\left.R^{2} 1 \cdot 0\right)$. All five rate constants were attributable to two incubations with abnormal standard hay values.

There was a close relationship between the in vitro gas production parameters and voluntary feed intake (Table 2 ). The correlations were obtained by a stepwise multiple regression procedure with equation parameters as independent variables and voluntary feed intake as dependent variable. 
Table 1. Means and ranges of parameters $\mathrm{A}, \mathrm{B},(\mathrm{A}+\mathrm{B}), \mathrm{c}, \mathrm{A}^{\mathrm{NDF}}, \mathrm{B}^{\mathrm{NDF}},\left(\mathrm{A}^{\mathrm{NDF}}+\mathrm{B}^{\mathrm{NDF}}\right)$ and $\mathrm{c}^{\mathrm{NDF}}$ in the in vitro gas production model $\mathrm{Y}=\mathrm{A}+\mathrm{B}\left(1-e^{-\mathrm{ct}}\right)$ when applied to $200 \mathrm{mg}$ substrate for $96 h^{*}$

\begin{tabular}{llcc}
\hline \hline Parameter & Mean & Minimum & Maximum \\
\hline$A$ & -3.1 & -9.9 & 2.7 \\
$B$ & 54.7 & 33.6 & 74.0 \\
$(A+B)$ & 51.6 & 33.3 & 68.7 \\
$C$ & 0.0493 & 0.032 & 0.0650 \\
$A^{\mathrm{NDF}}$ & -9.0 & -16.2 & -1.3 \\
$B^{\mathrm{NDF}}$ & 67.8 & 46.0 & 91.9 \\
$\left(A^{\mathrm{NDF}}+B^{\mathrm{NDF}}\right)$ & 59.0 & 41.0 & 79.3 \\
$c^{\mathrm{NDF}}$ & 0.0434 & 0.0149 & 0.0653 \\
\hline \hline
\end{tabular}

* Samples were obtained from fifty-four roughages and roughage neutral-detergent fibres. Quantity $Y=$ volume of gas produced (m), $t=$ time of incubation (h) and $A, B, c, A^{\mathrm{NDF}}, B^{\mathrm{NDF}}$ and $c^{\mathrm{NDF}}$ are constants.

About $75 \%$ of the variation in voluntary feed intake was accounted for by the in vitro gas production parameters $A, B$ and $c$. More of the variation in DMI was explained $(75 \% v$. $62 \%$ ) when $A$ and $B$ were entered as separate parameters into the models. The rate constant $c$ only attained a significance $(P<0.007)$ in model 1 (Table 2$)$ and contributed $6.5 \%$ to the variation in DMI accounted for. As a single factor in the regression $c$ accounted for $33.8 \%$ of the variation in DMI.

In vitro gas production from NDF explained more $(82 \% v .75 \%)$ of the variation in DMI than gas production from whole roughage. The extent of NDF fermentation $\left(A^{\mathrm{NDF}}+B^{\mathrm{NDF}}\right)$ accounted for $78 \%$ of the variation in DMI. The rate of gas production from NDF $\left(c^{\mathrm{NDF}}\right)$ improved the correlation significantly $(P<0-001)$; however, the overall

Table 2. Stepwise multiple correlations $\left(\mathrm{R}^{2}\right)$ between the parameters $\mathrm{A}, \mathrm{B},(\mathrm{A}+\mathrm{B}), \mathrm{c}, \mathrm{A}^{\mathrm{NDF}}$ $\mathrm{B}^{\mathrm{NDF}},\left(\mathrm{A}^{\mathrm{NDF}}+\mathrm{B}^{\mathrm{NDF}}\right)$ and $\mathrm{c}^{\mathrm{NDF}}$ as defined in Table 1 and the dry matter intake $(D M I)$ of fifty four roughages

\begin{tabular}{|c|c|c|c|}
\hline Parameter & $Y$ variate & $R^{2}$ & $P<$ \\
\hline$A+B+c$ & DMI (g/kg LW per d) & 0.747 & 0.0001 \\
\hline $\begin{array}{l}\text { 1. } B \\
\text { 2. } A \\
\text { 3. } C\end{array}$ & " & $\begin{array}{l}0.462^{*} \\
0.220^{*} \\
0.065^{*}\end{array}$ & $\begin{array}{l}0.0001 \\
0.0001 \\
0.0007\end{array}$ \\
\hline$(A+B)+c$ & $"$ & 0.623 & 0.0001 \\
\hline $\begin{array}{l}\text { 1. }(A+B) \\
\text { 2. } c\end{array}$ & " & $\begin{array}{l}0.601 * \\
0.022 *\end{array}$ & $\begin{array}{l}0.0001 \\
0.085\end{array}$ \\
\hline$A^{\mathrm{NDF}}+B^{\mathrm{NDF}}+c^{\mathrm{NDF}}$ & $\mathrm{DMI} \mathrm{g} / \mathrm{kg} \mathrm{LW}$ per d) & 0.793 & 0.0001 \\
\hline $\begin{array}{l}\text { 1. } B^{\mathrm{NDF}} \\
\text { 2. } c^{\mathrm{NDF}} \\
\text { 3. } A^{\mathrm{NDF}}\end{array}$ & " & $\begin{array}{c}0.766^{*} \\
0.027^{*} \\
\text { NS }\end{array}$ & $\begin{array}{c}0.0001 \\
0.013 \\
\text { NS }\end{array}$ \\
\hline$\left(A^{\mathrm{NDF}}+B^{\mathrm{NDF}}\right)+c^{\mathrm{NDF}}$ & $"$ & 0.822 & 0.0001 \\
\hline $\begin{array}{l}\text { 1. }\left(A^{\mathrm{NDF}}+B^{\mathrm{NDF}}\right) \\
\text { 2. } c^{\mathrm{NDF}}\end{array}$ & " & $\begin{array}{l}0.781^{*} \\
0.041^{*}\end{array}$ & $\begin{array}{l}0.0001 \\
0.0012\end{array}$ \\
\hline
\end{tabular}


contribution to the explained variance was small (4.1\%) (Table 2). As a single factor $c^{\text {NDF }}$ accounted for $57.5 \%$ of the variation in DMI.

\section{Intercorrelations between equation parameters}

The equation parameters were statistically interdependent (Table 3). Extent and rate of gas production of roughages and roughage NDF were positively associated.

Relationships between in vitro gas production at various times of incubation and voluntary feed intake

When whole roughage was incubated, all the gas volumes measured at the twelve incubation times, and used to fit the exponential equation, were significantly $(P<0.0001)$ related to DMI (Fig. 1).

Maximum correlation between gas volumes and intake occurred at $8 \mathrm{~h}$ incubation $\left(R^{2} 0.75\right)$ in whole roughages; thereafter the variance accounted for was less. The variation explained by gas volumes other than that at $8 \mathrm{~h}$ varied between 61 and $68 \%$ (Fig. 1).

Gas volumes from the incubation of NDF were also significantly $(P<0.001)$ related to intake at all fermentation times measured. The $R^{2}$ increased with time of incubation until it reached a reasonably constant value at $30 \mathrm{~h}$ of incubation and beyond $\left(R^{2} 0.81-0.82\right)$. Again more of variation (by $7 \%$ ) was explained by the fermentation of NDF than by the fermentation of unextracted material.

Early stages of in vitro fermentation and true substrate degradability at 24 h of incubation

Gas volumes from the incubation of $500 \mathrm{mg}$ substrate ranged from 36.5 to $105.6 \mathrm{ml}$ in $24 \mathrm{~h}$ incubation. Gas volumes at all incubation times were significantly $(P<0.0001)$ correlated with feed intake. Maximum correlation occurred at $6 \mathrm{~h}$ incubation when $77 \%$ of the variation in DMI was accounted for. Equally good predictors of DMI were gas volumes at $4\left(R^{2} 0.74\right)$ and $8 \mathrm{~h}\left(R^{2} 0.75\right)$ incubation. Thereafter the coefficient of correlation decreased.

Table 3. Intercorrelations* $(\mathrm{r})$ between parameters $\mathrm{A}, \mathrm{B},(\mathrm{A}+\mathrm{B})$ and $\mathrm{c}$ and between parameters $\mathrm{A}^{\mathrm{NDF}}, \mathrm{B}^{\mathrm{NDF}},\left(\mathrm{A}^{\mathrm{NDF}}+\mathrm{B}^{\mathrm{NDF}}\right)$ and $\mathrm{c}^{\mathrm{NDF}}$, as defined in Table 1

\begin{tabular}{|c|c|c|c|c|}
\hline \multicolumn{5}{|c|}{ Model $Y=A+B\left(1-\mathrm{e}^{-c t}\right)$} \\
\hline Parameter & $A$ & $\boldsymbol{B}$ & $\begin{array}{l}A- \\
+B\end{array}$ & $c$ \\
\hline $\begin{array}{l}A \\
B \\
A+B \\
c\end{array}$ & $\begin{array}{r}1.000 \\
-0.615 \\
-0.397 \\
-0.475\end{array}$ & $\begin{array}{l}1.000 \\
0.968 \\
0.640\end{array}$ & $\begin{array}{l}1.000 \\
0.593\end{array}$ & 1.000 \\
\hline \multicolumn{5}{|c|}{ Model $Y=A^{\mathrm{NDF}}+B^{\mathrm{NDF}}\left(1-\mathrm{e}^{-\mathrm{cNDFt}}\right)$} \\
\hline Parameter & $A^{N D F}$ & $B^{\mathrm{NDF}}$ & $\left(A^{\mathrm{NDF}}+B^{\mathrm{NDF}}\right)$ & $c^{\mathrm{NDF}}$ \\
\hline $\begin{array}{l}A_{\mathrm{NDF}}^{\mathrm{ND}} \\
B^{\mathrm{NDF}} \\
\left(A^{\mathrm{NDF}}+B^{\mathrm{NDF}}\right) \\
c^{\mathrm{NDF}}\end{array}$ & $\begin{array}{r}1.000 \\
-0.930 \\
-0.869 \\
-0.807\end{array}$ & $\begin{array}{l}1.000 \\
0.979 \\
0.740\end{array}$ & $\begin{array}{l}1.000 \\
0.692\end{array}$ & 1.000 \\
\hline
\end{tabular}

* All relationships were significant $(P<0.05)$. 


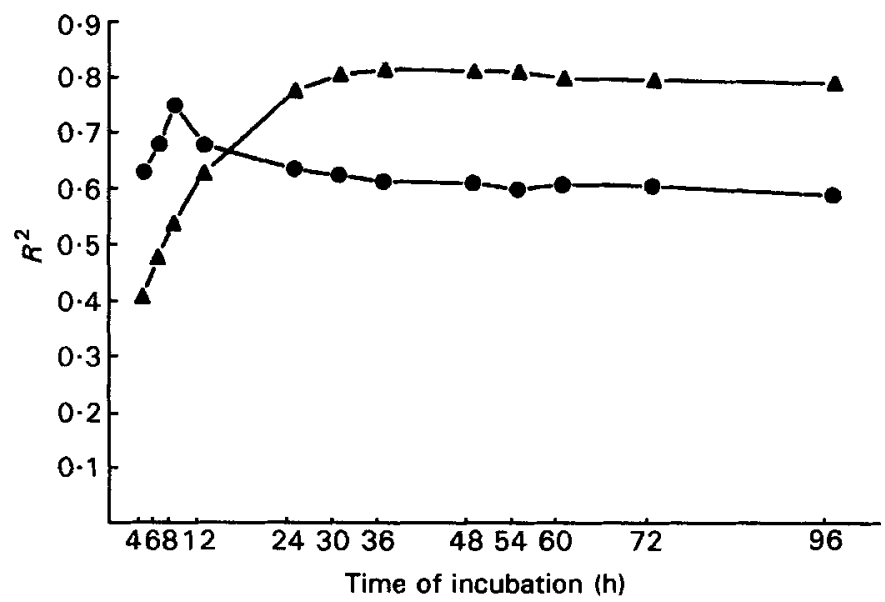

Fig. 1. Correlations $\left(\boldsymbol{R}^{2}\right)$ between in vitro gas volumes from fifty-four roughages $(\boldsymbol{\theta})$ and roughage neutral-detergent fibre fractions (A) measured at $4,6,8,12,24,30,36,48,54,60,72$ and $96 \mathrm{~h}$ incubation and dry matter intake.

In vitro DM true digestibility (TD) and NDF digestibility (NDF-D) were determined after terminating the incubation at $24 \mathrm{~h}$ and were calculated from the truly undegraded substrate. TD varied from 26.8 to $68.7 \%$ while NDF-D varied from 16.4 to $51.3 \%$. (The NDF content ranged from 64.8 to $87.5 \%$.)

The amount of DM truly degraded after $24 \mathrm{~h}$ explained $73 \%$ of the variation in feed intake whilst NDF-D accounted for $66 \%$ of the variation. NDF content as such explained $72 \%$ of the variability in feed consumption. More of the variation $(76 \%)$ was accounted from when NDF-D and NDF were combined. The combination of gas production at early hours of incubation with TD and NDF-D improved the correlation with DMI at 4 $(P<0.001)$ and $6(P<0.01) \mathrm{h}$ of incubation and at 4,6 and $8 \mathrm{~h}$ respectively (Table 4$)$. All other combinations and/or relationships gave non-significant responses.

Gas production at all incubation times was significantly intercorrelated with NDF-D and TD $(P<0.0001)$. The correlation $(r)$ between gas volumes and NDF-D and TD increased with time of incubation from 0.78 to 0.95 and from 0.83 to 0.97 respectively.

Table 4. Percentage of statistical variation in voluntary feed intake explained by gas production after various periods of in vitro fermentation in combination with neural-detergent fibre degradabilities (NDF-D) and true degradability (TD)

(Data were obtained by digesting $500 \mathrm{mg}$ substrate for $24 \mathrm{~h}$ )

\begin{tabular}{lcclll}
\hline \hline Gas production & $4 \mathrm{~h}+$ NDF-D & $79.0 \%$ & Improvement* & $4.7 \%$ & $P<0.001$ \\
Gas production & $6 \mathrm{~h}+$ NDF-D & $79.0 \%$ & Improvement & $2.5 \%$ & $P<0.01$ \\
Gas production & $4 \mathrm{~h}+\mathrm{TD}$ & $80.5 \%$ & Improvement & $6.1 \%$ & $P<0.001$ \\
Gas production & $6 \mathrm{~h}+\mathrm{TD}$ & $\mathbf{8 0 . 3 \%}$ & Improvement & $3.7 \%$ & $P<0.01$ \\
Gas production & $8 \mathrm{~h}+\mathrm{TD}$ & $77.8 \%$ & Improvement & $2.8 \%$ & $P<0.01$ \\
NDF-D & & $66.0 \%$ & & & $P<0.0001$ \\
NDF-D+NDF & & $76.0 \%$ & Improvement & $10 \%$ & $P<0.01$ \\
TD & & $73.0 \%$ & & & $P<0.0001$ \\
\hline
\end{tabular}

* Improvement in percentage of variation in dry-matter intake explained by the combination of the second parameter with the first. 


\section{DISCUSSION}

\section{Extent and rate of in vitro gas production as described by the exponential equation} $\mathrm{Y}=\mathrm{A}+\mathrm{B}\left(l-e^{-\mathrm{ct}}\right)$ and the prediction of dry-matter intake

The exponential model $Y=A+B\left(1-\mathrm{e}^{-c t}\right)$ in general fitted well the cumulative gas production with time; the $R^{2}$ for the overall goodness-of-fit for the model was high $\left(R^{2}>0.98\right)$. Within the forty stovers incubated twice, the extent of gas production $A+B$ was little affected by variation in the activity of rumen fluid collected on different days. There was, however, an influence on the rate of fermentation. Lower reproducibility of rates compared with extent of fermentation were also reported by Pell \& Schofield (1993) for gas volume measurements and by Nocek (1985) and Fadel (1992) for in sacco kinetic parameters. Pell \& Schofield (1993) reported run-to-run related covariances of $25-5 \%$ in incubations up to $30 \mathrm{~h}$, the highest covariance being associated with incubation times up to $10 \mathrm{~h}$. A covariance of the rate of gas production of $6.3 \%$ (including the two runs which were to be repeated) in the present study therefore seemed reasonable. There is, however, a need for a control standard to detect differences in the incubations.

The mean values for the intercept $A$ were negative in the incubation of whole stovers; all intercepts were negative in the case of NDF (Table 1). Negative intercepts do not agree with the concept of $A$ directly reflecting the fermentation of the soluble part of the feed. Negative $A$ values are encountered also in nylon bag work ( $\varnothing$ rskov \& Ryle, 1990) and are due to a deviation from an exponential course of fermentation. The onset of fermentation can be delayed due to microbial colonization (Chesson \& Forsberg, 1988) or a lag can occur after the soluble part of the substrate has been consumed but the fermentation of the cell walls has not yet started. In the work presented here, gas volumes recorded at 4, 6, 8 and $12 \mathrm{~h}$ of fermentation were not correlated $\left(R^{2} 0.03-0.035\right)$ with $A$; obviously low as well as higher initial gas volumes could lead to negative $A$ values. These findings suggest that sigmoidal models might provide a better description of gas profiles than exponential models. However, of the $75 \%$ of the variation in feed intake explained by the parameters $A, B$ and $c$ (Table 2), $A$ accounted for $22 \%$. The statistical relevance of $A$ probably lies in indicating the deviation from the exponential course of fermentation. Dhanoa (1988), for example, reported a highly significant correlation between lag phase and $A$ value for in sacco degradabilities. Considering only one gas pool $(A+B$, Table 2$)$ resulted in a lower correlation (62 v. $75 \%$, Table 2 ) which was probably due to the loss of information conveyed by $A$. These results support the assumption that $A$ reflects some relevant information. Gas volumes described by $B$ accounted for $46 \%$ of the variance. The rate of fermentation proved to be of less importance, since $c$ accounted for only $6.5 \%$ of the variation (in the model) in DMI.

The variation in DMI was explained to a higher extent $(7 \%)$ by gas production parameters from the incubation of NDF than by those from whole-roughage incubations. These findings agree with the general concept that roughage intake is restricted by rumen fill as suggested by many workers and with the dominant role of NDF in intake regulation in particular (Mertens, 1973, 1987; Osbourn, 1978). Depending on the model, 79.3 or $82.2 \%$ of the variation in DMI was accounted for (Table 2). Treating $A^{\mathrm{NDF}}+B^{\mathrm{NDF}}$ as one parameter resulted in a slightly higher correlation. The extent of in vitro gas volume from NDF accounted for $78.1 \%$ of the variation in DMI, the inclusion of the rate of cell-wall fermentation into the model significantly improved the correlation $(4 \cdot 1 \%) . A^{\mathrm{NDF}}$ as single factor did not attain a significant level when entered with $B^{\mathrm{NDF}}$ and $c^{\mathrm{NDF}}$ (Table 2). In this model, $76.6 \%$ was accounted for by $B^{\mathrm{NDF}}$ and $2.7 \%$ by $c^{\mathrm{NDF}}$. The soluble fraction of the feed is, of course, extracted by treatment with neutral detergent in the preparation of the 
cell walls. Since there is no rapidly fermentable substrate left, the parameter $A^{\mathrm{NDF}}$ may be redundant, since the fraction whose variability it probably reflects is removed. The inclusion of the rate constant $c^{\mathrm{NDF}}$ was, in both cases, statistically significant but the overall contribution of the rate constant to the variation was again small compared with the variance accounted for by the parameters related to extent of NDF fermentation.

The use of the exponential model $Y=A+B\left(1-\mathrm{e}^{-c t}\right)$ has been criticized, for example by Dhanoa (1988) and France et al. (1993), for coping insufficiently with the initial phase of incubations, a criticism which agrees with the present reported findings of negative $A$ values. So far alternative models accommodating, for example, lag or sigmoidal fermentation phases (Beuvink \& Kogut, 1993; France et al. 1993) have not been compared with the exponential model in the prediction of DMI. Use of these alternative models may improve the prediction of DMI or shift statistical importance from one equation parameter to another, for example from extent to rate parameters.

\section{Interactions among extent and rates of gas production}

There was significant interaction between the equation parameters (Table 3). Roughages with a highly fermentable insoluble fraction were fermented faster than those with a lower fermentable fraction. Correlations followed the same trend in the NDF incubations but were higher throughout. Intercorrelations certainly render the kinetics of gas production as described by the exponential model less valuable in the evaluation of fermentations, since one parameter already contains, to some degree, information about the others. Unfortunately information on these interactions is not available in publications related to extent and rate of gas production (i.e. Xiong et al. 1990; Krishnamoorthy et al. 1991; Beuvink \& Kogut, 1993; France et al. 1993; Pell \& Schofield, 1993). Therefore, there is no information on whether the intercorrelation between rate and extent of in vitro gas production is peculiar to lower-quality roughages or a common feature in in vitro gas production tests. There was, for example, no significant correlation between the parameters $A, B$ and $c$ of ten straws as described by the in sacco technique (Ørskov et al. 1988); rate and extent of gas production of the same material however were intercorrelated $(P<0.05$; Blümmel \& Ørskov, 1993).

The interaction between rate and extent of in vitro gas production may be responsible for the small contribution of the rate constant $c$ to the variation in DMI when $c$ was combined with $A$ and $B$ in the stepwise multiple correlations (Table 2). The lower reproducibility of $c$ compared with $(A+B)$ of course may also contribute to this problem. However $c$ as a single parameter was significantly $(P<0.0001)$ related to DMI in both whole roughage $\left(R^{2} 0.34\right)$ as well as roughage NDF incubations $\left(R^{2} 0.58\right)$.

\section{Gas volumes at various incubation times, neutral-detergent fibre fermentations and dry-matter intake}

For whole roughage as well as for roughage NDF the use of a kinetic model of fermentation had no statistical advantage over some of the simple endpoint measurements (compare Fig. 1 and Table 2). It appears from the results presented in Fig. 1 that, for DMI prediction, gas volumes produced initially are more important in whole roughages while volumes measured after a longer period are important in extracted NDF. Roughages with high initial gas production probably have a high content of cell solubles. High asymptotic gas volumes from extracted NDF will reflect high degradabilities of structural roughage components. The amount of cell solubles and the degradability of NDF are two separate quality parameters (Van Soest, 1994). Gas profiles from whole roughage incubations only, 
seem inadequate to describe variations in these two parameters. The results shown in Fig. 1 suggest variations in extent of NDF fermentation to be more relevant for DMI predictions than variations in cell solubles content (see also Table 2).

It would be inaccurate to suggest $8 \mathrm{~h}$ of incubation (Fig. 1) of whole roughage to predict DMI. However, comparison between the results presented in Fig. 1 with those presented for the incubation of $500 \mathrm{mg}$ substrate suggests that the rather pronounced correlation peak reported in Fig. 1 is an artefact of the Menke et al. (1979) gas production system. Menke et al. (1979) derived their test from the Tilley \& Terry (1963) system, but changed the proportion of rumen fluid to substrate from about $10 \mathrm{ml}$ to $500 \mathrm{mg}$ sample to about $10 \mathrm{ml}$ to $200 \mathrm{mg}$. This was to compensate for the limited gas volume space in the 100 $\mathrm{ml}$ calibrated gas syringes they used. The high proportion of rumen microbes to substrate may be responsible for the peak-like correlation coefficient seen in Fig. 1.

Further evidence for the different fermentation pattern of $200 \mathrm{mg}$ substrate compared with higher substrate weights can be taken from Theodorou et al. (1994). Those workers incubated 200-2000 mg substrate (increasing the amount successively by $200 \mathrm{mg}$ ) in $10 \mathrm{ml}$ rumen fluid and $90 \mathrm{ml}$ medium in a pressure transducer system. It can be calculated from their data that the substrate:gas pool ratio for $200 \mathrm{mg}$ substrate was markedly different (3.45) from all other (400-2000 mg) ratios (4.11-4.45, mean 4.25, SD 0.12). It appears that a ratio of $200 \mathrm{mg}$ substrate $: 10 \mathrm{ml}$ rumen fluid gives proportionally different results from other concentrations.

The results presented in Fig. 1 were obtained from two independent incubations. NDF was extracted and incubated. NDF degradability at any given incubation time can also be determined in unextracted roughage by basically the same approach, namely refluxing with NDS. In other words the two important aspects about roughage fermentation presented in Fig. 1 may be captured in one single incubation. A combination of the early gas volumes with the concomitant NDF degradability at $24 \mathrm{~h}$ leads to improvement in the correlations with DMI (Table 4) compared with correlations obtained from gas production parameters of whole roughages only. A further improvement in the correlation might be made by quantifying the NDF residue at $30 \mathrm{~h}$ or later to provide a better prediction of the extent of NDF degradabilities in whole roughage. The correlation between in vitro gas production from extracted NDF and DMI was higher at $>30 \mathrm{~h}$ than at $24 \mathrm{~h}\left(R^{2} 0.82 v . R^{2} 0.78\right.$, Fig. 1). However, in vitro fermentation of unextracted and extracted NDF seems to differ (see later) and further work is needed to clarify this aspect.

\section{Neutral-detergent fibre fermentation as measured by in vitro gas production}

It is interesting that on average more gas $(59.0 \mathrm{ml})$ was produced from $200 \mathrm{mg}$ NDF than from $200 \mathrm{mg}$ whole roughage $(51.6 \mathrm{ml})$. Furthermore the gas was produced at a rate only about $12 \%$ lower (Table 1). Ash content is lower in NDF than in whole roughage (Van Soest, 1994) but this difference cannot explain the higher gas volume from NDF compared with whole roughage. This can be demonstrated by taking average roughage $(49.3 \%)$ and roughage NDF ( $34.8 \%$ ) digestibilities at $24 \mathrm{~h}$ (originating from data presented in Table 4). A $200 \mathrm{mg}$ portion of substrate would therefore supply 98.6 and $69.6 \mathrm{mg}$ digestible roughage and roughage NDF respectively. The average ash content of whole roughage was $7.3 \%$ and $200 \mathrm{mg}$ would contain $14.6 \mathrm{mg}$ ash thus reducing the amount of digestible substrate available for gas production to $84.0 \mathrm{mg}$; whole roughage therefore still supplies more digestible substrate than roughage NDF. (This calculation considers all the ash to be soluble in NDS, which is not the case, and $200 \mathrm{mg}$ NDF would supply less than $69.6 \mathrm{mg}$ digestible substrate.) 
A possible explanation for higher gas volumes from NDF may reside in the efficiency with which fermentable material is incorporated into microbial cells. Blümmel et al. (1994) pointed to a possible inverse relationship between gas production (i.e. short-chain fatty acid production) and microbial cell yield when both were related to a given unit of substrate truly fermented. Proportionally less microbial yield and higher SCFA production from NDF would therefore mean higher gas volumes from NDF. (This aspect is dealt with in more detail in a subsequent paper, Blümmel et al. 1997.)

The authors are thankful to Dr A. V. Goodchild from the International Center for Agricultural Research in the Dry Areas (ICARDA) for contributing many of the intake data. The comments and suggestions of Dr Alex McAllan and Professor John Topps on the manuscript are gratefully acknowledged.

\section{REFERENCES}

Beuvink, J. M. V. \& Kogut, J. (1993). Modelling gas production kinetics of grass silages incubated with buffered ruminal fluid. Journal of Animal Science 71, 1041-1046.

Blümmel, M. \& Ørskov, E. R. (1993). Comparison of in vitro gas production and nylon bag degradability of roughages in prediction of feed intake in cattle. Animal Feed Science and Technology 40, 109-119.

Blümmel, M., Steingass, H. \& Becker, K. (1994). The partitioning of in vitro fermentation products and its bearing for voluntary feed intake. Proceedings of the Society for Nutritional Physiology 3, 123 Abstr.

Blümmel, M., Steingass, H. \& Becker, K. (1997). The relationship between in vitro gas production, in vitro microbial biomass yield and ${ }^{15} \mathrm{~N}$ incorporation and its implications for the prediction of voluntary feed intake of roughages. British Journal of Nutrition 77 (In the Press).

Chesson, A. \& Forsberg, C. W. (1988). Polysaccharide degradation by rumen micro-organisms. In The Rumen Microbial Ecosystem, pp. 251-284 [P. N. Hobson, editor]. London and New York: Elsevier Applied Science.

Dhanoa, M. S. (1988). On the analysis of dacron bag data for low degradability feeds. Grass and Forage Science 43, $441-444$

Fadel, J. G. (1992). Application of theoretically optimal sampling schedule designs for fiber digestion estimation in sacco. Journal of Dairy Science 75, 2184-2189.

France, J., Dhanoa, M. S., Theodorou, M. K., Lister, S. J., Davies, D. R. \& Isac, D. (1993). A model to interpret gas accumulation profiles associated with in vitro degradation of ruminant feeds. Joumal of Theoretical Biology 163, 99-111.

Goering, H. K. \& Van Soest, P. J. (1970). Forage Fiber Analysis. Agricultural Handbook no. 379. Washington, DC: Agricultural Research Service, US Department of Agriculture

Khazaal, K., Dentinho, M. T., Ribeiro, J. M. \& Ørskov, E. R. (1993). A comparison of gas production during incubation with rumen contents in vitro and nylon bag degradability as predictors of apparent digestibility in vivo and the voluntary feed intake of hays. Animal Production 57, $105-112$.

Krishnamoorthy, U., Soller, H., Steingass, H. \& Menke, K. H. (1991). A comparative study on rumen fermentation of energy supplements in vitro. Journal of Animal Physiology and Animal Nutrition 65, 28-35.

Menke, K. H., Raab, L., Salewski, A., Steingass, H., Fritz, D. \& Schneider, W. (1979). The estimation of the digestibility and metabolizable energy content of ruminant feedstuffs from the gas production when they are incubated with rumen liquor. Journal of Agricultural Science 92, 499-503.

Mertens, D. R. (1973). Application of a theoretical model to cell wall digestion and forage intake in ruminants. PhD thesis, Cornell University, Ithaca, New York.

Mertens, D. R. (1987). Predicting feed intake and digestibility using mathematical models of rumen function. Journal of Animal Science 49, 1085-1095.

Minson, J. D. (1990). Forage in Ruminant Nutrition. San Diego: Academic Press, Inc.

Nocek, J. E. (1985). Evaluation of specific variables affecting in situ estimates of ruminal dry matter and protein digestion. Journal of Animal Science 60, 1347-1358.

Ørskov, E. R., Reid, G. W. \& Kay, M. (1988). Prediction of intake of cattle from degradation characteristics of roughages. Animal Production 46, 29-34.

Ørskov, E. R. \& Ryle, M. (1990). Energy Nutrition in Ruminants. London and New York: Elsevier Applied Science.

Osbourn, D. F. (1978). Principles governing the use of chemical methods for assessing the nutritive value of forages: a review. Animal Feed Science and Technology 3, 265.

Pell, A. N. \& Schofield, P. (1993). Computerizing monitoring of gas production to measure forage digestion in vitro. Joumal of Dairy Science 76, 1063-1073. 
Siaw, D. E. K., Osuji, P. O. \& Nsahlai, I. V. (1993). Evaluation of multipurpose tree germplasm: the use of gas production and rumen degradation characteristics. Journal of Agricultural Science, Cambridge 120, 319-330.

Statistical Analysis Systems (1988). SAS/STAT, version 6.1. Cary, NC: SAS Inc.

Theodorou, M. K., Williams, B. A., Dhanoa, M. S. \& McAllan, A. B. (1991). A new laboratory procedure for estimating kinetic parameters associated with the digestibility of forages. International Symposium on Forage Cell Wall Structure and Digestibility, B3. Madison, WI: US Dairy Forage Research Centre and USDA Agricultural Research Service.

Theodorou, M. K., Williams, B. A., Dhanoa, M. S., McAllan, A. B. \& France, J. (1994). A simple gas production method using a pressure transducer to determine the fermentation kinetics of ruminant feeds. Animal Feed Science and Technology 48, 185-187.

Tilley, J. M. A. \& Terry, R. A. (1963). A two stage technique for the in vitro digestion of forage crops. Journal of the British Grasslands Society 18, 104-111.

Van Soest, P. J. (1994). Nutritional Ecology of the Ruminant, 2nd ed. Ithaca, NY: Cornell University Press.

Van Soest, P. J., Mertens, D. R. \& Deimum, B. (1978). Preharvest factor influencing the voluntary feed intake of forages. Journal of Animal Science 47, 712-721.

Van Soest, P. J. \& Robertson, J. B. (1985). A Laboratory Manual for Animal Science 612. Ithaca, NY: Cornell University.

Xiong, Y., Bartle, J., Preston, R. L. \& Meng, Q. (1990). Estimating starch availability and protein degradation of steam-flaked and reconstituted sorghum grain through a gas production technique. Journal of Animal Science 86, $3880-3885$. 